ISSN (print): 2715-3177 | ISSN (online): 2614-8102

Program Studi Ekonomi Syariah, STAI Auliaurrasyidin Tembilahan Journal Homepage: https://ejournal.stai-tbh.ac.id/index.php/al-muqayyad

\title{
Pengaruh Sosialisasi Badan Amil Zakat Nasional terhadap Minat Muzaki Membayar Zakat
}

\author{
*Delvi Hamsiska Putri ${ }^{1,}$, Iwan Siswanto ${ }^{2, \text { b }}$, Seri Yanti Siagian ${ }^{3, c}$ \\ 1,2,3) STAI Auliaurrasyidin Tembilahan, Indragiri Hilir, Riau, Indonesia \\ Email: ${ }^{a}$ delvi282019@gmail.com; ${ }^{b}$ iwan.siswanto@stai-tbh.ac.id; ${ }^{c}$ seri.yanti@ stai-tbh.ac.id
}

\section{DOI:}

https://doi.org/10.469

63/jam.v4i1.342

\section{Cara Mensitasi Artikel ini:}

Putri, D. H, \& Siswanto, I., \& Siagian, S. Y. (2021). Pengaruh sosialisasi badan amil zakat nasional terhadap Minat Muzaki Membayar Zakat. AL-Muqayyad, 4(1), 1-13. https://doi.org/10.46963/jam.v4i1.342
Keywords:

Sosialiazation, BAZNAS, Interest, Zakat

Kata Kunci: Sosialisasi, BAZNAS, Minat, Zakat

\section{Informasi Artikel:} Diterima: 11/06/2021

Direvisi:

Diterbitkan 30/06/2021

\section{*Corresponding}

Author

delvi282019@gmail. com

\section{ABSTRACT}

This study aimed to determine whether the socialization of BAZNAS affects the interest of Muzaki in distributing zakat through the National Amil Zakat Agency of Indragiri Hilir Regency. This research was quantitative. The data were analyzed using a simple linear regression method with the help of the Statistical Product and Service Solutions (SPSS) 23. The results of the data analysis showed the tcount was 20.985 so that, ttable $1.651<$ tcount 20.985 with a significance of 0.000 under 0.05. Thus, it concluded that the socialization of BAZNAS on the interest of Muzaki in paying zakat through the National Amil Zakat Agency in Tembilahan City has a significant influence.

\section{ABSTRAK}

Penelitian ini bertujuan untuk mengetahui apakah sosialisasi BAZNAS berpengaruh terhadap minat muzaki menyalurkan zakat melalui Badan Amil Zakat Nasional Kabupaten Indragiri Hilir. Jenis penelitian ini adalah penelitian kuantitatif. Data dianalisa menggunakan metode regresi linear sedehana dengan Program Statistical Product and Servisce Solutions (SPSS) 23. Hasil Analisa data menunjukkan nilai thitung sebesar 20,985 sehingga, ttabel 1,651 < thitung 20,985) dengan signifikansi 0,000 berada dibawah 0,05. Dengan demikian, dapat disimpulkan bahwa sosialisasi BAZNAS terhadap minat muzaki membayar zakat melalui Badan Amil Zakat Nasional di Tembilahan Kota mempunyai pengaruh yang signifikan.

\section{PENDAHULUAN}

Setiap Muslim mengakui bahwa zakat merupakan salah satu tiang penyangga tegaknya Islam yang wajib ditunaikan. Harta yang dikeluarkan zakatnya akan menjadi berkah, tumbuh, berkembang dan bertambah, suci dan beres (baik). Bahwa sebagian di antara umat Islam memahami bahwa zakat memiliki makna yang sama dengan infak yaitu memberikan, mengeluarkan, membelanjakan sebagian dari harta benda untuk tujuan kebaikan baik berupa pembangunan sarana atau fasilitas sosial (umum) maupun untuk membantu kelompok-kelompok tertentu (Muhammad, 2007). 
Delvi Hamiska Putri; Iwan Siswanto; \& Seri Yanti Siagian

Zakat merupakan sejumlah harta tertentu yang diwajibkan oleh Allah SWT, untuk diberikan kepada para mustahik yang disebutkan dalam Al-Quran. Zakat merupakan kewajiban bagi setiap Muslim (khususnya yang kepemilikannya telah mencapai nisab). Zakat lebih informal daripada infak dan shadaqah, karena jumlah nisab, angka/kadar zakat yang dapat dizakati dan kepada siapa zakat akan dibagikan sudah dinyatakan dalam hukum. Orang yang tidak mau mengeluarkan zakat, berarti ia telah mengkhianati keislaman dan keimanannya. Apalagi zakat selain berdimensi ibadah mahdhah, juga memiliki dimensi sosial karena zakat termasuk salah satu ibadah yang bersifat qadha'iy, yaitu ibadah yang jika tidak dilaksanakan, akan ada hak orang lain yang terambil yaitu hak para mustahik. Oleh karena itu, ancaman dan hukuman bagi orang yang tidak mengeluarkan zakat akan sangat berat, baik hukuman di dunia maupun di akhirat kelak (Ahmad Hasan Ridwan, 2013).

Dengan jumlah penduduk Indonesia yang mayoritas muslim, sehingga dapat dijadikan peluang pengumpulan dana zakat untuk meningkatkan perkembangan ekonomi di Indonesia. Dan dapat membantu pemerintah dalam memberantas kemiskinan di Indonesia. Allah SWT telah memerintahkan dalam surah An-Nur ayat 56:

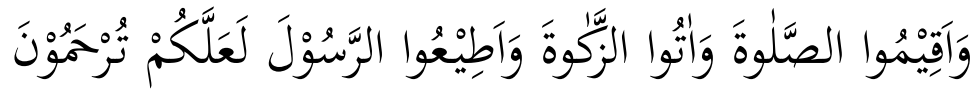

Artinya: "Dan laksanakan shalat, tunaikanlah zakat, dan taatlah kepada Rasul (Muhammad), agar kamu diberi rahmat”.(Q.S. An-Nur : 56)

Dari ayat di atas telah dijelaskan bahwa seorang muslim diperintahkan untuk menunaikan zakat. Dengan adanya lembaga-lembaga tempat penyaluran zakat mempermudah dalam penyaluran zakat, seperti Badan Amil Zakat Nasional.

Organisasi pengelola zakat di Indonesia antara lain adalah BAZNAS (Badan Amil Zakat Nasional) serta Baitul Mal. Zakat sebagai suatu kekuatan aktual umat Islam perlu dikelola dengan suatu sistem manajemen seperti yang digunakan dalam bidang perekonomian masyarakat lainnya. Informasi menjadi inti dari kegiatan perzakatan. Agar informasi yang dibutuhkan tersedia, maka zakat harus diserahkan kepada pemegang pembukuan yang menulis semua transaksi perzakatan. Badan Amil Zakat Nasional (BAZNAS) merupakan lembaga tempat penyaluran dana zakat, yang dapat membantu muzaki dalam mengelola dana zakat yang akan disalurkan kepada mustahik.

\section{Al-Muqayyad}

Vol. 4 No. 1 (2021) 
Pengaruh Sosialisasi Badan Amil Zakat Nasional Terhadap Minat Muzaki Membayar Zakat

Persoalan yang menjadi problematika zakat adalah rendahnya tingkat pengetahuan umat Islam tentang zakat. Banyak orang yang beranggapan, bahwa pengetahuan tentang zakat hanyalah dibebankan terhadap orang-orang tertentu saja. Bahkan, banyak umat Islam yang tidak mengetahui, disengaja ataupun tidak tentang nisab dan haul. Lembaga-lembaga konsultasi zakat yang ada belum sepenuhnya mampu mensosialisasikan pengetahuan tentang zakat kepada masyarakat. Sementara, perkembangan sistem ekonomi setiap hari terus bertambah dan bervariasi.

Masih ada sebagian orang yang belum menyalurkan dana zakat kepada Badan Amil Zakat Nasional (BASNAZ). Karena kurangnya pengetahuan masyarakat tentang lembaga Amil Zakat tersebut. Dengan mensosialisasikan Badan Amil Zakat Nasional (BASNAZ) setidaknya membuat masyarakat lebih mengetahui lebih jauh tentang pengelolaan dana zakat di Badan Amil Zakat Nasional (BASNAZ).

Dalam rangka manajemen zakat pasar atau pemasaran adalah berkaitan dengan upaya-upaya peningkatan penyadaran muzaki menyetorkan zakatnya kepada Badan/Lembaga Amil Zakat melalui berbagai kegiatan sosialisasi, seperti melalui media dakwah, media cetak, media elektronik, program unggulan, penciptaan event, dan lainlain. Dari sini pun hendaknya mulai disosialisasikan bahwa suksesnya manajemen zakat dalam merealisasikan maksud dan tujuannya akan berpengaruh besar dalam kehidupan masyarakat Muslim, dan juga dalam menyelesaikan problematika kemasyarakatan dalam mengentaskan kemiskinan dan mengentaskan kelemahan materi dan psikologi (Yusuf Qaradhawi, 2005).

Tabel 1.1

Jumlah Muzaki (Orang yang Membayar Zakat) di Badan Amil Zakat Nasional (BAZNAS) Kabupaten Indragiri Hilir

\begin{tabular}{|c|c|c|c|}
\hline Tahun & Jenis Kelamin & Jumlah & Total Muzaki \\
\hline \multirow{2}{*}{2017} & Laki-Laki & 763 & \multirow{2}{*}{1250} \\
\hline & Perempuan & 487 & \\
\hline \multirow{2}{*}{2018} & Laki-Laki & 783 & \multirow{2}{*}{1280} \\
\hline & Perempuan & 497 & \\
\hline \multirow{2}{*}{2019} & Laki-Laki & 831 & \multirow{2}{*}{1321} \\
\hline & Perempuan & 490 & \\
\hline
\end{tabular}

Sumber data: BAZNAS Kabupaten Indragiri Hilir 
Tabel 1.2

Jumlah Kegiatan Sosialisasi BAZNAS Kabupaten Indragiri Hilir Periode 2017-2019

\begin{tabular}{|c|c|c|}
\hline No & Tahun & Kegiatan Sosialisasi \\
\hline 1. & 2017 & $15 \mathrm{kali}$ \\
\hline 2. & 2018 & $13 \mathrm{kali}$ \\
\hline 3. & 2019 & $10 \mathrm{kali}$ \\
\hline
\end{tabular}

Sumber data: BAZNAS Kabupaten Indragiri Hilir

Tabel 1.3

Data Pengumpulan Dana Zakat BAZNAS Kabupaten Tembilahan Periode 2017-2019

\begin{tabular}{|c|c|c|}
\hline No & Tahun & Dana yang terkumpul \\
\hline 1. & 2017 & Rp. 2.785 .250 .000 \\
\hline 2. & 2018 & Rp.3.951.543.000 \\
\hline 3. & 2019 & Rp. 3.302.265.000 \\
\hline
\end{tabular}

Sumber data: BAZNAS Kabupaten Indragiri Hilir

Dari tabel 1.1, tabel 1.2, dan tabel 1.3, dapat dilihat bahwa jumlah muzaki pada tahun 2017-2019 terdapat peningkatan. Pada tahun 2017 jumlah muzaki 1.250 dengan jumlah kegiatan sosialisasi yang dilaksanakan sebanyak 15 kali, tahun 2018 jumlah muzaki 1.280 dengan jumlah sosialisasi yang dilaksanakan sebanyak 13 kali, dan pada tahun 2019 jumlah muzaki meningkat menjadi 1.321 dengan jumlah sosialisasi yang dilaksanakan sebanyak 10 kali.

Dan pada tabel 1.3 pengumpulan dana zakat di badan amil zakat nasional (BAZNAS) Kabupaten Indragiri Hilir dalam tiga tahun terakhir yaitu periode tahun 20172019 pengumpulan dana zakat mengalami perubahan dari tahun ke tahun penaikan dan penurunan. Pada bulan Juni tahun 2017 jumlah dana yang terkumpul yaitu Rp. 2.785.250.000, pada tahun 2018 dana yang terkumpul yaitu Rp. 3.951.543.000, dan pada tahun 2019 dana zakat yang terkumpul mengalami penurunan yaitu Rp. 3.302.265.000.

Berdasarkan hal di atas, penulis tertarik untuk melakukan suatu penelitian dengan judul Pengaruh Sosialisasi Badan Amil Zakat Nasional Terhadap Minat Muzaki Membayar Zakat Melalui Badan Amil Zakat Nasional di Tembilahan Kota. Dan berdasarkan uraian di atas, penulis dapat mengemukakan rumusan masalah yaitu sebagai

\section{Al-Muqayyad}

Vol. 4 No. 1 (2021) 
Pengaruh Sosialisasi Badan Amil Zakat Nasional Terhadap Minat Muzaki Membayar Zakat

berikut: Apakah terdapat Pengaruh Sosialisasi Badan Amil Zakat Nasional terhadap minat muzaki membayar zakat melalui Badan Amil Zakat Nasional di Tembilahan Kota?

Adapun tujuan yang ingin dicapai oleh peneliti dalam penelitian diantaranya: Untuk mengetahui pengaruh sosialisasi badan amil zakat nasional terhadap minat muzaki membayar zakat melalui badan amil zakat nasional di Tembilahan Kota.

\section{METODE}

Jenis penelitian ini adalah penelitian kuantitatif. Metode penelitian kuantitatif adalah metode penelitian yang berlandaskan pada filsafat positivisme, digunakan untuk meneliti pada populasi atau sampel tertentu, pengumpulan data menggunakan instrumen penelitian, analisis data bersifat kuantitatif/statistik, dengan tujuan untuk menguji hipotesis yang diterapkan (Sugiyono, 2016).

Dalam penelitian ini menjelaskan tentang pengaruh sosialisasi badan amil zakat nasional terhadap minat muzaki membayar zakat melalui badan amil zakat nasional di Tembilahan Kota.

Penelitian ini dilaksanakan pada Lembaga Badan Amil Zakat Nasional (BASNAZ) Kabupaten Indragiri Hilir di JL. Letda M. Boya No. 282 Tembilahan Kota. Populasi dalam penelitian ini yaitu seluruh muzaki di Badan Amil Zakat Nasional (BASNAZ) Tembilahan berjumlah 1.321 muzaki. Karena jumlah muzaki terlalu besar, maka peneliti mengambil beberapa jumlah sampel yang dapat mewakili seluruh populasi. Penarikan sampel dalam penelitian ini menggunakan tabel Isaac dan Michael dengan taraf kesalahan 10\%, yaitu dengan jumlah sampel 227 orang.

Dalam penelitian ini, penulis menggunakan kuesioner dan dokumentasi sebagai teknik pengumpulan data. Kuesioner yang digunakan yaitu dengan bentuk pertanyaan tertutup. Pertanyaan tertutup adalah pertanyaan yang mengharapkan jawaban singkat atau mengharapkan responden untuk memilih salah satu alternatif jawaban dari setiap pertanyaan yang telah tersedia. Skala pengukuran yang digunakan dalam penelitian tersebut adalah skala pengukuran likert dengan alternatif penilaian 1 sampai 5 kategori yang mempunyai gradasi dari sangat positif sampai sangat negatif.

Teknik analisis data yang digunakan yaitu regresi linier sederhana. Regresi linier sederhana didasarkan pada hubungan fungsional ataupun kausal satu variabel independen dengan satu variabel dependen. Dalam penelitian ini menggunakan Aplikasi SPSS 0.23. 
Delvi Hamiska Putri; Iwan Siswanto; \& Seri Yanti Siagian

\section{HASIL DAN PEMBAHASAN}

\section{Uji validitas}

Uji validitas merupakan suatu ukuran yang menunjukkan tingkat keandalan atau keabsahan suatu alat ukur. Validitas digunakan untuk mengetahui kelayakan butir-butir dalam suatu daftar (konstruk) pertanyaan dalam mendefinisikan suatu variabel.

Tabel I.4

Hasil uji validitas variabel $(\mathbf{X})$

\begin{tabular}{|c|c|c|c|c|}
\hline Variabel & $\begin{array}{c}\text { No. butir } \\
\text { Item }\end{array}$ & $\begin{array}{c}\text { Item-item } \\
\text { correlation }\end{array}$ & R Tabel & Keterangan \\
\hline \multirow{4}{*}{ Sosialisasi } & 1 & 0,647 & 0,130 & Valid \\
\cline { 2 - 5 }$(\mathbf{X})$ & 2 & 0,717 & 0,130 & Valid \\
\cline { 2 - 5 } & 3 & 0,612 & 0,130 & Valid \\
\cline { 2 - 5 } & 4 & 0,234 & 0,130 & Valid \\
\cline { 2 - 5 } & 5 & 0,488 & 0,130 & Valid \\
\cline { 2 - 5 } & 6 & 0,394 & 0,130 & Valid \\
\cline { 2 - 5 } & 7 & 0,708 & 0,130 & Valid \\
\cline { 2 - 5 } & 8 & 0,395 & 0,130 & Valid \\
\cline { 2 - 5 } & 9 & 0,195 & 0,130 & Valid \\
\hline
\end{tabular}

Sumber: Hasil penelitian 2020 (Data olah)

Berdasarkan tabel I.4, hasil uji validitas pada variabel (X) dapat diketahui bahwa semua indikator yang digunakan untuk mengukur variabel-variabel yang digunakan dalam penelitian ini memiliki koefisien korelasi yang lebih besar dari $r$ tabel $=0,130$, maka dapat dinyatakan semua indikator valid.

Tabel I.5

Hasil uji validitas variabel (Y)

\begin{tabular}{|c|c|c|c|c|}
\hline Variabel & $\begin{array}{c}\text { No. Butir } \\
\text { Item }\end{array}$ & $\begin{array}{c}\text { Item-item } \\
\text { correlation }\end{array}$ & R Tabel & Keterangan \\
\hline Minat & 1 & 0,261 & 0,130 & Valid \\
\cline { 2 - 5 } $\begin{array}{c}\text { Membayar } \\
\text { Zakat (Y) }\end{array}$ & 2 & 0,238 & 0,130 & Valid \\
\cline { 2 - 5 } & 3 & 0,400 & 0,130 & Valid \\
\cline { 2 - 5 } & 4 & 0,286 & 0,130 & Valid \\
\cline { 2 - 5 } & 5 & 0,245 & 0,130 & Valid \\
\cline { 2 - 5 } & 6 & 0,407 & 0,130 & Valid \\
\cline { 2 - 5 } & 7 & 0,553 & 0,130 & Valid \\
\cline { 2 - 5 } & 8 & 0,519 & 0,130 & Valid \\
\cline { 2 - 5 } & 9 & 0,324 & 0,130 & Valid \\
\hline
\end{tabular}

Sumber: Hasil penelitian 2020 (Data olah)

\section{Al-Muqayyad}

Vol. 4 No. 1 (2021) 
Berdasarkan tabel I.5, hasil uji validitas pada variabel (Y) dapat diketahui bahwa semua indikator yang digunakan untuk mengukur variabel-variabel yang digunakan dalam penelitian ini memiliki koefisien korelasi yang lebih besar dari $r$ tabel $=0,130$, maka dapat dinyatakan semua indikator valid.

\section{Uji reliabilitas}

Tabel I.6

Hasil uji reliabilitas

\begin{tabular}{|l|c|c|c|}
\hline \multirow{2}{*}{ Variabel } & \multicolumn{2}{|c|}{ Hasil Reability ( Alpha) } & \multirow{2}{*}{ Keterangan } \\
\cline { 2 - 3 } & Kriteria & Cronbach's alpha & \\
\hline $\begin{array}{l}\text { Variabel Independen: } \\
\text { Sosialisasi (X) }\end{array}$ & 0,60 & 0,622 & Reliabel \\
\hline $\begin{array}{l}\text { Variabel Dependen } \\
\text { Minat Membayar Zakat (Y) }\end{array}$ & 0,60 & 0,616 & Reliabel \\
\hline
\end{tabular}

Dari tabel I.6, diketahui bahwa variabel sosialisasi (X) menunjukkan nilai reliabilitas 0,62 dan variabel minat membayar zakat (Y) menunjukkan nilai reliabilitas 0,61. Dan berarti nilai kedua variabel lebih besar dari cronbach Alpha >0,60 yang berarti semua variabel reliabel.

\section{Koefisien determinasi $\left(\mathbf{R}^{\mathbf{2}}\right)$}

Nilai koefisien determinasi $\left(\mathrm{R}^{2}\right)$ adalah 0,662 dan setelah dikaitkan pada tabel interpretasi nilai koefisien determinasi pada interval 0,6 - 0,799 yaitu pada kategori kuat ketepatannya. Hal tersebut berarti memberikan indikasi bahwa kontribusi variabel (X) terhadap variabel (Y) adalah sekitar $66,2 \%$, sedangkan sisanya 33,8\% yang dipengaruhi oleh variabel lain.

\section{Uji t}

Hasil uji t, bahwa $t_{\text {hitung }}$ pada variabel sosialisasi (X) adalah 20,985. Pada derajat bebas $(\mathrm{df})=\mathrm{N}-2=227-2=225$, maka dapat diketahui tabel sebesar 1,651. Jadi dari keterangan tersebut dapat disimpulkan bahwa $t_{\text {hitung }}>t_{\text {tabel }}(20,985>1,651)$, dengan sig $(0,000)$ lebih kecil dari $(0,05)$ maka dengan demikian $\mathrm{H}_{0}$ ditolak dan $\mathrm{H}_{\mathrm{a}}$ diterima. Sehingga dapat diambil kesimpulan bawah variabel sosialisasi (X) mempunyai pengaruh yang signifikan terhadap variabel minat membayar zakat (Y). 
Delvi Hamiska Putri; Iwan Siswanto; \& Seri Yanti Siagian

Pembahasan dalam penelitian ini menunjukkan apakah ada pengaruh antara sosialisasi terhadap minat muzaki membayar zakat. Setelah dilakukan penelitian dengan data-data yang terkumpul diketahui bahwa sosialisasi berpengaruh signifikan terhadap minat muzaki membayar zakat melalui badan amil zakat nasional (BAZNAS).

Teknik analisis data yang digunakan dalam penelitian yaitu dengan menggunakan analisis regresi linier sederhana, yang dibantu dengan program software SPSS 0.23, dengan persamaan regresi linier sederhana yaitu: $\mathbf{Y}=\mathbf{a}+\mathbf{b X}$

Tabel I.7

Hasil Uji Analisis Regresi Linier Sederhana

Coefficients $^{\mathbf{a}}$

\begin{tabular}{|c|c|c|c|c|c|c|}
\hline \multirow{2}{*}{\multicolumn{2}{|c|}{ Model }} & \multicolumn{2}{|c|}{$\begin{array}{l}\text { Unstandardized } \\
\text { Coefficients }\end{array}$} & \multirow{2}{*}{$\begin{array}{c}\text { Standardized } \\
\text { Coefficients }\end{array}$} & \multirow[b]{2}{*}{$\mathrm{T}$} & \multirow[b]{2}{*}{ Sig. } \\
\hline & & B & Std. Error & & & \\
\hline \multirow[t]{2}{*}{1} & (Constant) & 7.544 & 1.650 & & 4.571 & .000 \\
\hline & $\begin{array}{l}\text { SOSIALISA } \\
\text { SI }\end{array}$ & .816 & .039 & .814 & 20.985 & .000 \\
\hline
\end{tabular}

Hasil yang diperoleh menunjukkan bahwa variabel sosialisasi (X) memiliki tingkat signifikan yang lebih besar dari (0.05), maka dapat disimpulkan bahwa ada pengaruh signifikan terhadap minat membayar zakat $(Y)$. Diketahui nilai $(a=7,544)$ dan nilai $(b=0,816)$. Jika variabel sosialisasi $(X)$ ditingkatkan 1 satuan skala likert, maka minat membayar zakat (Y) akan meningkat sebesar 0,816 .

Untuk melakukan pengujian terhadap pengaruh sosialisasi terhadap minat muzaki membayar zakat digunakan pengujian menggunakan uji t, dengan tingkat keyakinan $95 \%$.

Tabel I.8

Hasil dari uji t

Coefficients $^{\mathrm{a}}$

\begin{tabular}{|c|c|c|c|c|c|c|}
\hline \multirow{2}{*}{\multicolumn{2}{|c|}{ Model }} & \multicolumn{2}{|c|}{$\begin{array}{c}\text { Unstandardized } \\
\text { Coefficients }\end{array}$} & \multirow{2}{*}{$\begin{array}{c}\begin{array}{c}\text { Standardized } \\
\text { Coefficients }\end{array} \\
\text { Beta }\end{array}$} & \multirow[b]{2}{*}{$\mathrm{t}$} & \multirow[b]{2}{*}{ Sig. } \\
\hline & & $\mathrm{B}$ & Std. Error & & & \\
\hline \multirow[t]{2}{*}{1} & (Constant) & 7.544 & 1.650 & & 4.571 & .000 \\
\hline & $\begin{array}{l}\text { SOSIALISA } \\
\text { SI }\end{array}$ & .816 & .039 & .814 & 20.985 & .000 \\
\hline
\end{tabular}

Berdasarkan tabel tentang hasil uji $\mathrm{t}$, bahwa thitung pada variabel sosialisasi $(\mathrm{X})$ adalah 20,985. Pada derajat bebas $(\mathrm{df})=\mathrm{N}-2=227-2=225$, maka dapat diketahui $t_{\text {tabel }}$ sebesar 1,651. Jadi dari keterangan tersebut dapat disimpulkan bahwa $t_{\text {hitung }}>t_{\text {tabel }}$

\section{Al-Muqayyad}

Vol. 4 No. 1 (2021) 
Pengaruh Sosialisasi Badan Amil Zakat Nasional Terhadap Minat Muzaki Membayar Zakat

$(20,985>1,651)$, dengan sig $(0,000)$ lebih kecil dari $(0,05)$ maka dengan demikian $\mathrm{H}_{0}$ ditolak dan $\mathrm{H}_{\mathrm{a}}$ diterima. Sehingga dapat diambil kesimpulan bawah variabel sosialisasi (X) mempunyai pengaruh yang signifikan terhadap variabel minat membayar zakat (Y).

Teori-teori dalam penelitian yaitu tentang sosialisasi dan minat muzaki membayar zakat:

1. Sosialisasi

a. Pengertian sosialisasi

Sosialisasi adalah suatu proses interaksi sosial dengan mana orang memperoleh pengetahuan, sikap, nilai, dan perilaku esensial untuk keikutsertaan (partisipasi) efektif dalam masyarakat”.

b. Proses sosialisasi

Proses sosialisasi adalah suatu proses yang terjadi pada pendatang atau seorang anggota baru dalam suatu masyarakat yang mempelajari norma-norma dan kebudayaan masyarakat di tempat tinggalnya. Sosialisasi menjadi penting karena manusia tidak dapat hidup sendiri dan sosialisasi diperlukan untuk mengantisipasi agar perbedaan dari setiap individu tidak melahirkan pertentangan.

Tujuan dilakukannya sosialisasi dengan strategi-strategi tertentu ialah untuk menarik minat suatu kelompok atau masyarakat umum agar menjadi bagian dari suatu program ataupun menggunakan produk yang di sosialisasikan tersebut.

c. Sosialisasi yang dilakukan Badan Amil Zakat Nasional Tembilahan

Sosialisasi yang dilakukan Badan Amil Zakat Nasional Tembilahan dengan beberapa cara yaitu:

1) Membuat brosur yang bertujuan memperkenalkan kepada masyarakat tentang suatu lembaga zakat.

2) Bersosialisasi sekaligus mengadakan pendistribusian dana zakat

3) Menyampaikan ceramah-ceramah tentang zakat kepada masyarakat.

4) Menggunakan media massa seperti Koran, maksudnya untuk menghimbau para muzaki untuk menyalurkan zakatnya. 
Delvi Hamiska Putri; Iwan Siswanto; \& Seri Yanti Siagian

2. Minat muzaki membayar zakat

a. Pengertian zakat

Zakat adalah memberikan (menyerahkan) sebagian harta tertentu untuk orang tertentu yang telah ditentukan syara' dengan niat karena Allah. Zakat terbagi menjadi dua, yaitu zakat fitrah dan zakat maal.

b. Golongan yang berhak menerima zakat

Adapun delapan golongan yang berhak menerima zakat adalah sebagai berikut:

1) Fakir, orang yang tidak memiliki harta untuk mencukupi kebutuhan dirinya dan keluarganya, seperti makanan, minuman, pakaian, dan tempat tinggal.

2) Orang miskin, orang yang tidak memiliki harta untuk mencukupi kebutuhan dirinya dan keluarganya, seperti makanan, minuman, pakaian, dan tempat tinggal.

3) Amil zakat, orang yang bekerja dan sibuk mengurusi zakat, seperti orang yang menjaga, mengumpulkan, dan membawa zakat kepada imam, menulis, dan membagikannya.

4) Muallaf, mereka yang diharapkan kecenderungan hatinya atau keyakinannya dapat bertambah terhadap Islam, terhalangnya niat jahat mereka atas kaum muslimin, atau harapan akan adanya kemanfaatan mereka dalam membela dan menolong kaum muslimin dari musuh.

5) Budak, seorang muslim yang menjadi budak, lalu dibeli dari harta zakat dan dibebaskan di jalan Allah.

6) Orang yang berhutang, orang yang memiliki utang bukan untuk bermaksiat kepada Allah dan Rasul-Nya dan tidak sanggup melunasinya.

7) Fi sabilillah, orang-orang yang berperang di jalan Allah secara suka rela. Mereka diberi bagian zakat yang dapat dipergunakan untuk memenuhi keperluan perang, seperti membeli senjata, kendaraan, memenuhi kebutuhan hidupnya dan keluarganya.

8) Ibnu Sabil, musafir yang tidak dapat melanjutkan perjalanannya di negeri lain. Mereka diberi zakat agar memiliki bekal untuk kembali ke negerinya.

\section{Al-Muqayyad}

Vol. 4 No. 1 (2021) 
Pengaruh Sosialisasi Badan Amil Zakat Nasional Terhadap Minat Muzaki Membayar Zakat

3. Faktor-faktor yang mempengaruhi minat

Faktor-faktor yang mempengaruhi timbulnya minat menurut Crow and Crow yaitu:

a. Dorongan dari dalam diri individu, misal dorongan makan, rasa ingin tahu dan seks. Muzaki yang telah mengetahui tentang kewajiban terhadap harta yang dimilikinya, dan dengan ada kesadaran dalam individu muzaki, maka muzaki senantiasa memiliki komitmen untuk mengeluarkan zakat setiap tahunnya.

b. Motif sosial, dapat menjadi faktor yang membangkitkan minat untuk melakukan suatu aktivitas tertentu. Dorongan dari luar sangat menentukan seseorang untuk membayar zakat, misalkan dorongan dari keluarga, teman, dan dorongan dari lingkungan sekitarnya.

c. Faktor emosional, minat mempunyai hubungan yang erat dengan emosi. Setiap muzaki yang mengeluarkan zakat pasti akan dilipat gandakan hartanya oleh Allah, dan muzaki mengharapkan balasan dari Allah.

\section{SIMPULAN}

Berdasarkan hasil penelitian mengenai pengaruh sosialisasi badan amil zakat nasional terhadap minat muzaki membayar zakat melalui Badan Amil Zakat Nasional di Tembilahan Kota yang telah dibahas serta perhitungan-perhitungan statistik menguji hipotesis yang telah dilakukan dengan analisis regresi linear sederhana dan pembahasan analisis data yang dilakukan, maka dapat ditarik kesimpulan yaitu, Sosialisasi (X) berpengaruh secara parsial dan signifikan terhadap minat membayar zakat (Y) melalui Badan Amil Zakat Nasional (BAZNAS) di Tembilahan Kota, hal tersebut ditunjukkan dengan nilai thitung sebesar 20,985. Jika variabel sosialisasi (X) ditingkatkan 1 satuan skala likert, maka minat membayar zakat (Y) akan meningkat sebesar 0,816.

Dari hasil uji t, nilai signifikan lebih kecil dari $0.05(0.000<0.5)$ artinya terdapat pengaruh signifikan antara sosialisasi $(\mathrm{X})$ terhadap minat membayar zakat $(\mathrm{Y})$.

\section{REFERENSI}

Asnaini. A. (2017). Minat muzaki membayar zakat melalui lembaga (Studi Kasus di Provinsi Bengkulu). Nuansa : Jurnal Studi Islam dan Kemasyarakatan, 10(7), 6674. http://dx.doi.org/10.29300/nuansa.v10i1.637

Bungin, B. (2010). Metodologi Penelitian Kuantitatif. Jakarta: Prenada Media Groub. 
Delvi Hamiska Putri; Iwan Siswanto; \& Seri Yanti Siagian

Damsar. (2011). Pengantar Sosiologi Pendidikan. Jakarta: Kencana.

Departemen Agama RI. (2008). Al-Quran dan Terjemahnya. Bandung: CV Diponegoro.

Fahmi, Z., \& Nur, M. M. (2018). Pengaruh Pengetahuan, Pendapatan, dan Kepercayaan, terhadap Minat Muzakki dalam Membayar Zakat di Baitul Mal Kota Lhokseumawe. Jurnal Ekonomi Regional Unimal, 1(3), 89-99. https://doi.org/10.29103/jeru.v1i3.592

Hafidhuddin, D. (2002). Zakat Dalam Perekonomian Modern. Jakarta: Gema Insani.

Halin, H., Wijaya, H., \& Yusilpi, R. (2017). Pengaruh Harga Jual Kaca Patri Jenis Silver Terhadap Nilai Penjualan Pada CV Kurnia Kaca Palembang 2004-2005. Jurnal Ecoment Global: Kajian Bisnis dan Manajemen, 2(2), 49-56. http://dx.doi.org/10.35908/jeg.v2i2.251

Hanurawan, Fattah. (2010). Psikologi Sosial. Bandung: PT Remaja Rosdakarya.

Hasan, Fuad, dkk. (2003). Kamus Istilah Psikologi. Jakarta: Progres.

Kokom, K., \& Subekti, P. (2016). Penggunaan Media Massa Sebagai Agen Sosialisasi Dinas Kesehatan Kabupaten Tasikmalaya Dalam Meningkatkan Kesadaran Masyarakat Akan Pentingnya Imunisasi. Profesi humas: Jurnal Ilmiah Ilmu hubungan masyarakat, 1(1), 12-21. https://doi.org/10.24198/prh.v1i1.9502

Mu'is, F. (2011). Zakat A-Z: Panduan Mudah, Lengkap, dan Praktis tentang Zakat. Solo: Tinta Medina.

Muhammad. (2007). Aspek Hukum Dalam Muamalat. Yogyakarta: Graha Ilmu.

Mujahidin, A. (2013). Ekonomi Islam: Sejarah, Konsep, Instrumen, Negara, dan Pasar. Jakarta: PT Raja Grafindo Persada.

Noor, J. (2011). Metodelogi Penelitian Skripsi, Tesis, Disertasi dan Karya Ilmiah. Jakarta: Kencana Prenada Media Group.

Qaradhawi, Y. (2005). Spektrum Zakat Dalam Membangun Ekonomi Kerakyatan. Jakarta: Zikrul Hakim.

Ridwan, M. (2014). Manajemen Baitul Maal Wa Tamwil (BMT). Yogyakarta: UII Press.

Ridwan., \& Ahmad, H. (2013). Manajemen Baitul Mal Watamwil. Bandung: CV Pustaka Setia.

Rifa'I, M. (1978). Ilmu Fiqih Islam Lengkap. Semarang: PT Karya Toha Putra.

Rozalinda. (2016). Fikih Ekonomi Syariah: Prinsip dan Implementasinya Pada Sektor. Jakarta: Rajawali Pers.

Setiadi M. Elly, dkk. (2006). Ilmu Sosial dan Budaya Dasar. Jakarta: Kencana.

Siregar, Syofian. (2013). Metode Penelitian Kuantitatif: Dilengkapi Perbandingan Al-Muqayyad

Vol. 4 No. 1 (2021) 
Pengaruh Sosialisasi Badan Amil Zakat Nasional Terhadap Minat Muzaki Membayar Zakat

Perhitungan Manual dan SPSS. Jakarta : KENCANA.

Slameto. (2013). Belajar Dan Faktor-Faktor Yang Mempengaruhinya. Jakarta: PT Rineka Cipta.

Sugiyono. (2016). Metode Penelitian Kuantitatif, Kualitatif, dan $R \&$ D. Bandung: Alfabeta.

Sugiyono. (2016). Metode Penelitian Manajemen. Bandung: Alfabeta.

Sugiyono. (2016). Statistika Untuk Penelitian. Bandung: Alfabeta.

Sunjoyo, dkk. (2013). Aplikasi SPSS Untuk Smart Riset. Bandung: Alfabeta. 